\title{
13.1
}

\section{Лазерно-индуцированные пространственно-периодические структуры на поверхности титана в среде н-гексана при различном давлении}

\author{
(ㄱ Д.А. Кочуев, К.С. Хорьков, А.С. Черников, Р.В. Чкалов, В.Г. Прокошев \\ Владимирский государственный университет им. А.Г. и Н.Г. Столетовых, Владимир, Россия \\ E-mail:_b_@mail.ru
}

Поступило в Редакцию 22 января 2020г.

В окончательной редакции 29 апреля 2020 г.

Принято к публикации 8 мая 2020г.

\begin{abstract}
Представлены результаты обработки фемтосекундным лазерным излучением поверхности титана в среде н-гексана при различном давлении. Рассмотрено влияние лазерно-индуцированной плазмы на характер формирования поверхностно-периодических структур в диапазоне давлений от 6 mbar до 22 bar. Исследование поверхности обработанных образцов проводилось с помощью растровой электронной микроскопии. Показана зависимость периода полученных лазерно-индуцированных поверхностных структур от давления в рабочем сосуде и режима обработки.
\end{abstract}

Ключевые слова: лазерно-индуцированные поверхностно-периодические структуры, фемтосекундное лазерное излучение, н-гексан, лазерная плазма.

DOI: 10.21883/PJTF.2020.15.49751.18213

Лазерное структурирование является универсальным и эффективным способом обработки материалов для придания поверхности новых функциональных свойств [1]. Формирование лазерно-индуцированных поверхностных периодических структур (ЛИППС) представляет собой одно из перспективных направлений современных исследований в области фотоники, плазмоники и наноматериаловедения. Данный подход позволяет получать упорядоченные микро- и наноструктуры на поверхности различных материалов с высокой производительностью и воспроизводимостью [2-4].

В настоящее время существует несколько подходов к объяснению механизмов формирования ЛИППС на поверхности металлов. Многократно подтвержденной экспериментально является интерференционная модель процесса образования периодических структур $[5,6]$. Согласно данной модели, формирование ЛИППС происходит при интерференции воздействующего излучения и возбужденной поверхностной электромагнитной волны. При рассеянии падающего излучения на неоднородностях рельефа поверхности возбуждаются поверхностные плазмоны, которые могут интерферировать с падающим излучением.

Помимо интерпретации физического процесса образования поверхностно-периодических структур под действием лазерного излучения существует проблема формирования ЛИППС с заданной периодичностью. Период подобных структур зависит от длины волны [7], мощности лазерного излучения [8] и угла падения [9], а формирующиеся в зоне облучения дорожки выстраиваются в зависимости от ориентации плоскости поляризации лазерного излучения $[10,11]$. Обычно изменение выходных параметров лазерных систем, особенно фемтосекундных, влияющих на изменение периода ЛИППС, затруднено для промышленного применения. Однако использование современных волоконных лазеров позволяет варьировать такие параметры без конструктивных изменений установки [12].

В большинстве работ, описывающих механизмы формирования ЛИППС, величина давления либо не упомянута вовсе, либо о ней говорится вскользь. Среди публикаций по формированию поверхностных периодических структур следует отметить работу [13], где показано изменение периода формируемых ЛИППС на кремнии в воздухе в зависимости от давления в пределах от атмосферных условий до значения $10^{-4}$ mbar. Показано, что при обработке в более разреженной среде пространственный период риппл-структур увеличивается, в то время как их глубина одновременно уменьшается.

Цель настоящей работы состоит в исследовании влияния внешнего давления в широком диапазоне значений и режима сканирования лазерного излучения на изменение периода лазерно-индуцированных поверхностных периодических структур при обработке материалов в жидкой реакционной среде.

При проведении обработки поверхности материалов ультракороткими лазерными импульсами с энергией, превышающей порог абляции, наблюдается образование плазменного факела. В работе [14] представлены экспериментальные значения мощности лазерного излучения, приводящей к оптическому пробою газов при различном давлении. Давление внешней среды оказывает влияние на распространение лазерно-индуцированного плазменного факела и соответственно вносит вклад в формирование лазерно-индуцированных поверхностных периодических структур.

Авторами предложен метод формирования ЛИППС заданного периода на поверхности титана в среде 


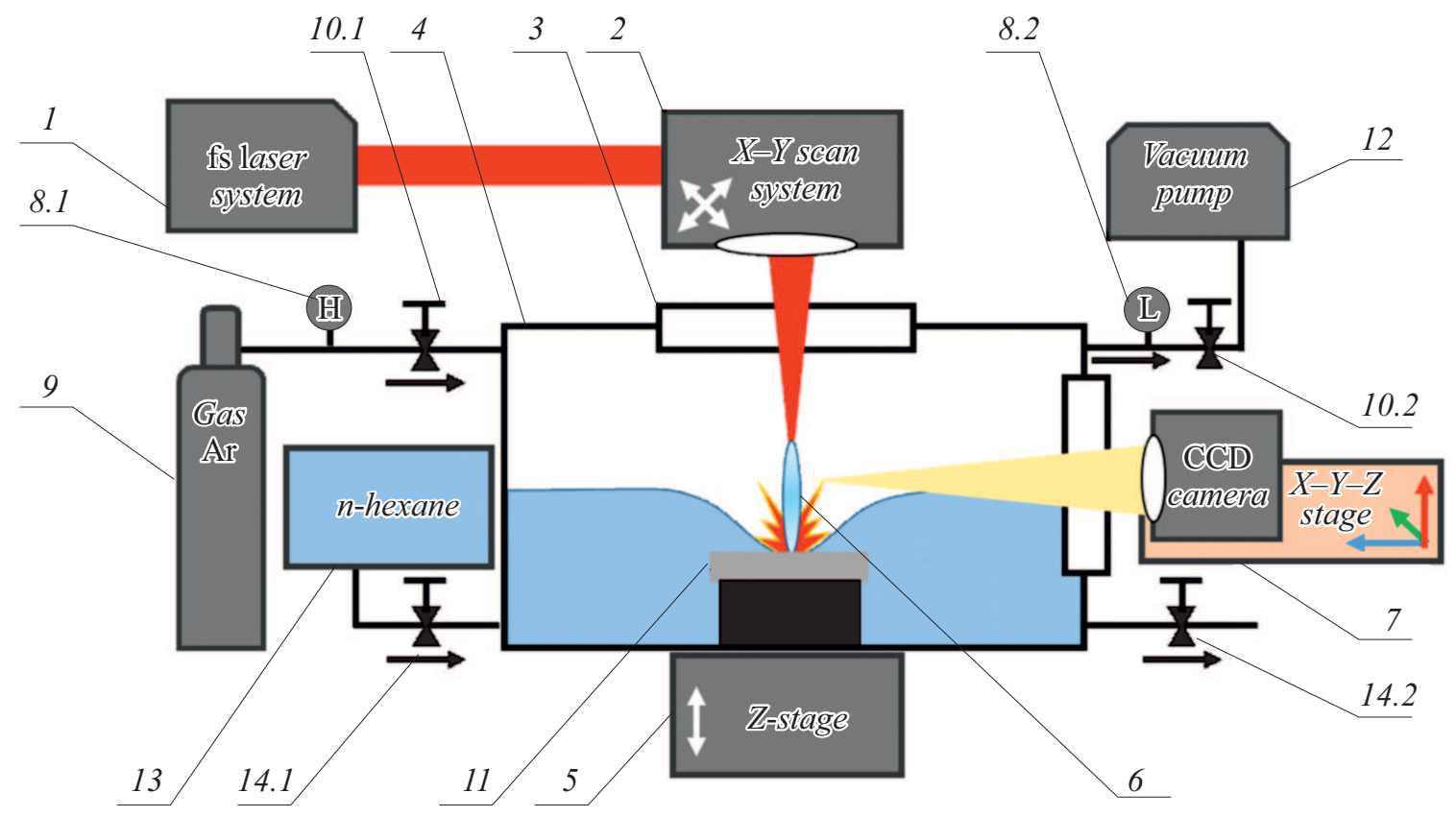

Pис. 1. Схема экспериментальной установки. Пояснения в тексте.

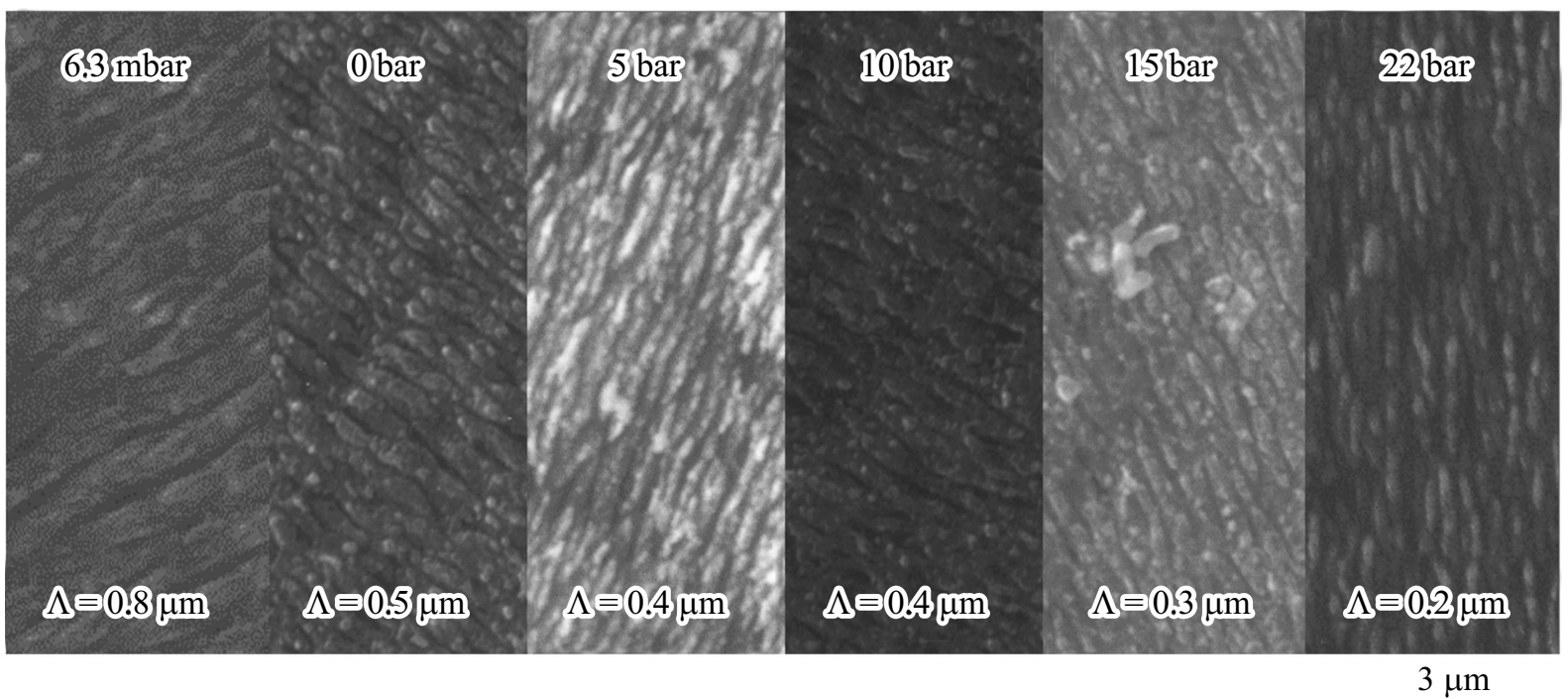

Рис. 2. РЭМ-изображения ЛИППС, полученных при скорости сканирования $10 \mathrm{~mm} / \mathrm{s}$.

н-гексана путем изменения давления в рабочем сосуде от $6 \mathrm{mbar}$ до $22 \mathrm{bar}$. Данные исследования являются продолжением работ, связанных с изучением взаимодействия фемтосекундного лазерного излучения с титаном в различных средах $[15,16]$. Использование в работе фемтосекундного лазерного излучения в н-гексане обусловлено необходимостью получения слоя карбида титана на обрабатываемой поверхности с целью защиты от окисления при атмосферных условиях. Облучение лазерным излучением наносекундной $(100 \mathrm{~ns}, 4 \mathrm{~mJ}, 10 \mathrm{kHz})$ или миллисекундной $(0.1 \mathrm{~ms}, 35 \mathrm{~J}, 10 \mathrm{~Hz})$ длительности не приводит к образованию карбида титана (наблю- дается образование углерода в фазе графита). Обработка поверхности титана в среде н-гексана для получения покрытия на поверхности титана подробно рассмотрена в [17].

Обработка поверхности титанового образца осуществлялась согласно схеме, представленной на рис. 1. В качестве изменяемой величины выступало давление буферного газа в сосуде в диапазоне от 6 mbar до 22 bar. Нижняя граница обусловлена физическими свойствами н-гексана: при дальнейшем снижении давления происходит интенсивное кипение жидкости, что согласуется с данными, приведенными в диаграмме Кокса для 


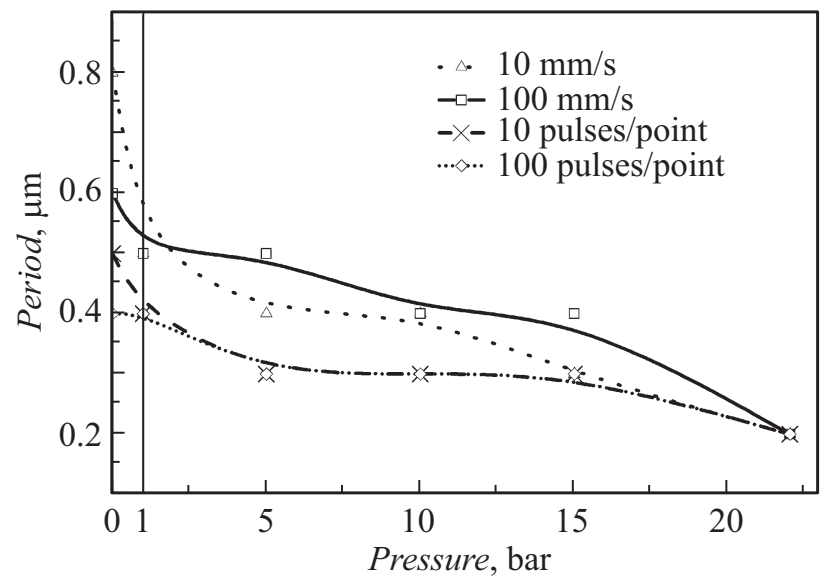

Рис. 3. Зависимость периода ЛИППС, полученных при различных режимах обработки, от давления.

н-гексана; верхняя граница (22 bar) обусловлена характеристиками используемой газовой арматуры. Обработка поверхности титана выполнялась с использованием фемтосекундной лазерной системы $1 \mathrm{c}$ энергией в импульсе $150 \mu \mathrm{J}$, частотой повторения импульсов $10 \mathrm{kHz}$, длиной волны $1030 \mathrm{~nm}$, длительностью импульса $280 \mathrm{fs}$. Развертка луча осуществлялась гальваносканатором 2. Диаметр луча на поверхности образца по уровню $90 \%$ мощности составлял $37 \mu \mathrm{m}$. Пучок имел гауссово распределение интенсивности излучения в поперечном сечении. Наблюдение процесса обработки и ввод лазерного излучения осуществлялись через окно 3 расположенного на боковых стенках и крышке изолированного сосуда 4. Для перемещения изолированного сосуда по вертикальной оси использовался линейный транслятор 5 . При обработке поверхности титанового образца 11 над поверхностью наблюдалось образование лазерноиндуцированного плазменного факела 6 . Процесс обработки регистрировался CCD-камерой 7. Давление в изолированном сосуде изменялось с использованием буферного газа 9, контроль давления производился датчиками 8.1 и 8.2 с помощью регулировки вентилей 10.1 и 10.2. Разрежение в сосуде создавалось вакуумным насосом 12. Заполнение изолированного сосуда н-гексаном происходило из емкости 13 , поддержка необходимого уровня осуществлялась вентилями 14.1 и 14.2.

Группа образцов обрабатывалась при различных режимах сканирования лазерным излучением. Проводилось исследование влияния скорости сканирования лазерного излучения 10 и $100 \mathrm{~mm} / \mathrm{s}$ и числа импульсов в область обработки 10 и 100. Образцы были обработаны в данных режимах при различном давлении. Поверхность обработанных образцов исследовалась с использованием растровой электронной микроскопии (РЭМ). На рис. 2 представлены снимки области поверхности, обработанной со скоростью $10 \mathrm{~mm} / \mathrm{s}$. На рис. 3 представлена зависимость периода ЛИППС от условий обработки. В процессе проведения обработки наблюдалось интенсивное кипение н-гексана до давления $5 \mathrm{bar}$, при дальнейшем повышении давления интенсивность кипения значительно снижалась. Предполагается, что основным фактором, влияющим на период формируемых структур, является давление внешней среды. В полученных экспериментах наблюдается разница периода ЛИППС, полученных при различном давлении, до 4 раз (от 0.8 до $0.2 \mu \mathrm{m}$ ) при неизменных режимах сканирования.

Величина давления влияет на плотность среды и скорость распространения лазерно-индуцированной плазмы, ее электронную плотность, ионную температуру и время жизни. Скорость разлета лазерно-индуцированной плазмы составляет от $10^{3}$ до $10^{7} \mathrm{~m} / \mathrm{s}[18,19]$. Лазерно-индуцированная плазма оказывает существенное влияние как на процесс обработки материалов, так и на свойства проходящего через нее лазерного излучения. При превышении порогового значения плотности мощности в среде наблюдается образование лазерно-индуцированных плазменных каналов. Увеличение плотности плазмы приводит к росту концентрации свободных электронов, значения диэлектрической проницаемости и, как следствие, изменению показателя преломления среды, что, согласно данным работ $[5,20]$, вносит основной вклад в изменение периода ЛИППС.

Таким образом, разработан метод изменения периода лазерно-индуцированных поверхностно-периодических структур на поверхности титана. Экспериментально получены ЛИППС с периодом от 0.2 до $0.8 \mu \mathrm{m}$ при изменении давления буферного газа в изолированном сосуде от $6 \mathrm{mbar}$ до 22 bar в среде н-гексана.

\section{Финансирование работы}

Работа выполнена в рамках государственного задания ВлГУ 3.5531.2017/8.9 ГБ-1106/17.

\section{Конфликт интересов}

Авторы заявляют, что у них нет конфликта интересов.

\section{Список литературы}

[1] Ионин А.А., Кудряшов С.И., Самохин А.А. // УФН. 2017. T. 187. № 2. C. 159-172.

[2] Bonse J., Kotera R., Hartelt M., Spaltmann D., Pentzien S., HöhmS., Rosenfeld A., Krüger J. // Appl. Surf. Sci. 2015. V. 336. P. 21-27.

[3] He X., Datta A., Nam W., Traverso L.M., Xu X. // Sci. Rep. 2016. V. 6. P. 35035.

[4] Gnilitskyi I., Derrien T.J.Y., Levy Y., Bulgakova N.M., Mocek T., Orazi L. // Sci. Rep. 2017. V. 7. P. 8485.

[5] Ахманов С.А., Емельянов В.И., Коротеев Н.И., Семиногов В.Н. // УФН. 1985. Т. 147. № 12. С. 675-745.

[6] Nathala C.S., Ajami A., Ionin A.A., Kudryashov S.I., Makarov S.V., Ganz T., Assion A., Husinsky W. // Opt. Express. 2015. V. 23. N 5. P. 5915-5929.

[7] Dar M.H., Saad N.A., Sahoo C., Naraharisetty S.R.G., Desai N.R. // Laser Phys. Lett. 2017. V. 14. N 2. P. 026101. 
[8] Bashir S., Rafique M.S., Nathala C.S., Ajami A.A., Husinsky W. // Physica B. 2017. V. 513. P. 48-57.

[9] Zhao Q.Z., Malzer S., Wang L.J. // Opt. Lett. 2007. V. 32. N 13. P. 1932-1934.

[10] Varlamova O., Reif J., Varlamov S., Bestehorn M. // Appl. Surf. Sci. 2011. V. 257. N 12. P. 5465-5469.

[11] Хорьков К.С., Кочуев Д.А., Черников А.С., Чкалов Р.В., Аракелян С.М., Прокошев В.Г. // Изв. РАН. Сер. физ. 2017. T. 81. № 12. C. 1630-1633.

[12] Ageev E.I., Veiko V.P., Vlasova E.A., Karlagina Y.Y., Krivonosov A., Moskvin M.K., Odintsova G.V., Pshenichnov V.E., Romanov V.V., Yatsuk R.M. // Opt. Express. 2018. V. 26. N 2. P. 2117-2122.

[13] Nivas J.J., Allahyari E., Gesuele F., Maddalena P., Fittipaldi R., Vecchione A., Bruzzese R., Amoruso S. // Appl. Phys. A. 2018. V. 124. N 2. P. 198.

[14] Аполлонов В.В., Плетнев Н.В. // Квантовая электроника. 2012. T. 42. № 2. C. 130-139.

[15] Абрамов Д.В., Аракелян С.М., Маков С.А., Прокошев В.Г., Хорьков К.С. // Письма в ЖТФ. 2013. Т. 39. В. 16. С. 14-22.

[16] Kochuev D.A., Khorkov K.S., Ivashchenko A.V., Prokoshev V.G., Arakelian S.M. // J. Phys.: Conf. Ser. 2018. V. 951. N 1. P. 012015.

[17] Кочуев Д.А., Хорьков К.С., Абрамов Д.В., Аракелян С.М., Прокошев В.Г. // Поверхность. Рентгеновские, синхротронные и нейтронные исследования. 2018. № 12. С. 8185.

[18] Бураков В.С., Буцень А.В., Тарасенко Н.В. // Изв. НАН Беларуси. Сер. физ.-мат. наук. 2015. № 3. С. 98-103.

[19] Талала К.А., Лейви А.Я., Яловеи, А.П. // Вестн. ЮУрГУ. Сер. Математика. Механика. Физика. 2012. № 34. С. 186190.

[20] Либенсон М.Н. // СОЖ. 1996. № 10. С. 92-98. 